\title{
Extubation of the Difficult Airway: An Algorithmic Approach
}

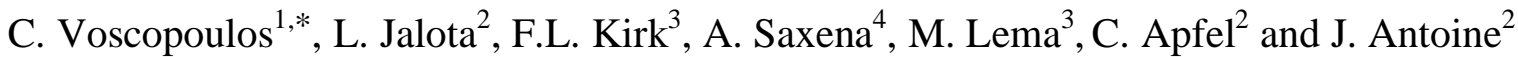

${ }^{1}$ Department of Anesthesiology, Perioperative and Pain Medicine, Brigham and Women's Hospital, Harvard Medical
School, Boston, Massachusetts, USA
${ }^{2}$ Perioperative Clinical Research Core, Department of Anesthesia and Perioperative Care, University of California at
San Francisco, San Francisco, California, USA
${ }^{3}$ Department of Anesthesiology, Critical Care, and Pain Medicine, University at Buffalo School of Medicine, Buffalo, New
York, USA
${ }^{4}$ University of California at San Francisco School of Medicine, San Francisco, California, USA

\begin{abstract}
The difficult airway has been defined as a "clinical situation in which a conventionally trained anesthesiologist experiences difficulty with mask ventilation of the upper airway, tracheal intubation, or both." Given the potentially lifethreatening consequences, the American Society of Anesthesiology has developed an airway algorithm that focuses on establishing an airway, generally for the induction of anesthesia. However, there is no algorithm on how to safely transition from an established airway back to the normal, natural airway. Up to 0.19 percent of patients can require reintubation in the post anesthesia recovery unit, with the known difficult airway at greater risk in these settings for failed reintubation. Because of this, there has been recognition of the need for guidelines in the form of an algorithm to deal with extubation in these patients. To fill this current need, we propose the following difficult to intubate patient extubation algorithm for use in the operating room setting.
\end{abstract}

Keywords: Difficult Intubation, Difficult Extubation, American Society of Anesthesiologist's (ASA) Difficult Airway Algorithm, Airway Exchange Catheter, Gum Elastic Bougie.

\section{INTRODUCTION}

Numerous papers and current guidelines regarding difficult airway management have focused on difficult tracheal intubation. As such, death/brain death claims from difficult airway management associated with induction of anesthesia decreased in 1993-1999 $(35 \%, \mathrm{n}=86)$ compared with 1985-1992 (67\%, $n=93)$, but not from other phases of anesthesia [1].This fall in claims for adverse events related to the induction of anesthesia may be attributable, in part, to the creation of algorithms and guidelines related to intubation [1-3]. However, to address the other phases of anesthesia related to difficult airway management, it is recognized that there is a need for the development of additional management strategies encountered during maintenance, emergence, and recovery.

To date, little guidance exists to address difficult tracheal extubation, despite the serious risk that exists with the difficult airway during this period $[4,5]$. Current prediction models for difficult airways have proven useful for the management of the difficult intubation, however, there is no evidence that they are useful for the prediction of difficult extubation. Given the numerous challenges regarding difficult extubation, a recent case report (with several additional supporting case reports) has specifically recognized the need

*Address correspondence to this author at the Department of Anesthesiology, Perioperative, and Pain Medicine, Brigham and Women's Hospital, Harvard Medical School, Boston, MA, USA; Tel: 617-732-8210; Fax: 617-730-9534;

E-mail: cjvoscopoulos@yahoo.com for guidelines and recommendations in the form of an algorithm to deal with extubation in these patients [1-4, 6-9].

A difficult airway has been defined as a "clinical situation in which a conventionally trained anesthesiologist experiences difficulty with mask ventilation of the upper airway, tracheal intubation, or both" [10] In general, in the operating room (OR) setting, up to 0.19 percent of patients can require reintubation [11-13]. In certain higher risk patient populations, such as liver transplantation, thoracic, otolaryngologic, or cardiac surgery, or in certain settings, such as airway or non-airway related complications of surgery or anesthesia, the reintubation rate can be even higher [12, 14-17]. Furthermore, tracheal reintubations are usually more intricate secondary to associated hypoxia, hypercapnia, possible hemodynamic instability, agitation, and airway obstruction. The patient with a known difficult airway is at greater risk in these settings for an even more difficult reintubation [11, 18-20].

In terms of reintubation rates, contrast is provided in the critical care setting, with up to $25 \%$ of surgical intensive care unit patients requiring reintubation after a planned extubation $[4,9,11,13,14,21-28]$. This said, it is recognized that a low reintubation rate in the intensive care unit (ICU) is not desirable, since this will increase the number of total days intubated with associated costs and risks. This situation is in contrast to the OR where the reintubation rate should be as low as possible. This point provides insight into the numerous physiologic and pathophysiologic differences between the ICU and OR patient. However, sometimes 
enough similarities exist where information may be able to be extrapolated from one experience to the other. Though our proposed algorithm here is for the difficult to extubate patient in the OR, frequent references are made to the ICU patient in an effort to help guide the management of the difficult to extubate OR patient, especially where research specific for the OR patient is lacking.

Though, to date, such an algorithm does not exist, both the American Society of Anesthesiologists (ASA) and Canadian Airway Focus Group recommend that an anesthesiologist should have a preformulated strategy for extubation of the difficult airway [10, 29]. Goals should include minimal discomfort and facilitation of oxygenation, ventilation, and, if needed, tracheal reintubation in a manner that provides for a "reversible tracheal extubation."

However, it is recognized that it is challenging to develop guidelines for the extubation of the patient with a difficult airway given the low incidence for the need of tracheal reintubation, the wide variety of possible clinical scenarios, the availability of equipment, and the training and experience of individual anesthesiologists [30]. Hence, any proposed algorithm needs to be modifiable to fit into a local culture, while concomitantly thinking globally on how to improve patients' long-term outcome [30]. In general, the development of algorithms follow the following steps: 1) identifying the problem, 2) selecting areas of performance improvement, 3) testing the strategy for change, 4) assessing data to determine whether performance is improved, 5) creating plans to implement improvement throughout the system, and 6) continuing to monitor effectiveness and make changes as needed [30].

Since sources cite the importance of having a strategy in place before extubation while no set guidelines exist, we propose the following difficult to intubate patient extubation airway algorithm, recognizing that this is an area of need of improvement, providing the best supportive evidence for decision points where available, while recognizing that prospective validation of this algorithm is ultimately needed.

\section{BODY}

Respiratory complications after tracheal extubation are three times more common than complications occurring during tracheal intubation and induction of anesthesia $(4.6 \%$ vs $12.6 \%)[31,32]$. Extubation in any patient should not occur until it has been determined that the patient can protect their airway and that the airway is patent. However, in the difficult to intubate patient, additional concerns must be considered.

According to the ASA, a strategy towards extubation of the difficult airway should include a plan that can be implemented if the patient is unable to maintain adequate oxygenation and/or ventilation after extubation, and the plan should include the short-term use of a device that can serve as a guide for expedited reintubation. This device may be "rigid to facilitate intubation and/or hollow to facilitate ventilation (2003 guidelines)." For this algorithm, the firstline device we suggest is the use of an airway exchange cathether (AEC) with an alternative secondary device, if an AEC is not available, a gum elastic bougie (GEB). In this article, GEB is broadly expanded to include all solid state tube exchangers and/or those without the ability to oxygenate or ventilate a patient.

As highlighted in a recent review article, the recommended technique by the ASA for extubation of the difficult airway utilizes an AEC [33]. This device is a hollow catheter that can be used for removal and replacement of tracheal tubes without the need for laryngoscopy (though concomitant use of laryngoscopy may increase the chances of a successful reintubation over such a device). The advantages of this device for extubation are that it can be placed long-term while waiting for airway edema to resolve, provides a conduit for reintubation, and allows for the ability to insufflate oxygen, administer jet ventilation, or reinstitute positive pressure ventilation, if needed $[9,34]$.

A GEB is a $60 \mathrm{~cm}$ long tracheal tube introducer that is a helpful tool for intubation, but it can also be used for extubation of the difficult airway, as it can serve as a reintubation guide [35]. Although it does not serve the functions of an AEC which allows for oxygen insufflation, jet ventilation, or positive pressure ventilation, the GEB is an option in settings where an AEC may not be available, or when the anesthesiologist is inexperienced with its use [35].

We make note here that not every difficult airway will require extubation over an AEC or GEB, and that the use of such devices precludes other options of airway management such as bag-mask ventilation or laryngeal mask airway (LMA) placement. Hence, the algorithm described below is for use only when the risk of failed extubation is high, and the perceived complexity of reintubation is deemed difficult with the possibility of failure by a conventionally trained anesthesiologist.

Lastly, extubation to an LMA is not listed in our algorithm as an option. Our algorithm is for the critical reintubation airway in the difficult to intubate patient, in which both supraglottic and infraglottic airway loss is possible, and the goal of a reliable reversible extubation method is sort. Since the LMA is at risk for failure in these situations, it is not recommended as an option in this patient population. We do make note, however, that perhaps in other, less critical airway situations, it may have a use [36-40]. Likewise, also for concern of losing a critical airway, deep extubations, which are the scenario in which endotracheal tubes (ETTs) are removed and LMAs are placed, are not recommended in our algorithm.

\section{ALGORITHM EXPLANATION}

As the algorithm demonstrates (Fig. 1), before extubating the patient with a difficult airway, one should call for assistance, have an emergency airway cart in the room (with equipment checked), suction the stomach, ensure adequate muscle paralysis reversal, prepare for a surgical airway, return the patient to spontaneous ventilation, perform aggressive suctioning of the oro/hypopharynx, ensure the patient is sufficiently awake to protect their airway by being able to follow three point commands, consider performing a cough test, as well as a cuff leak test, and consider the use of perioperative corticosteroids. Additionally, prior to the extubation of a potential difficult airway we recommend to assess/reassess the airway, as, especially in certain surgical procedures, such as otolaryngologic surgeries, the airway 


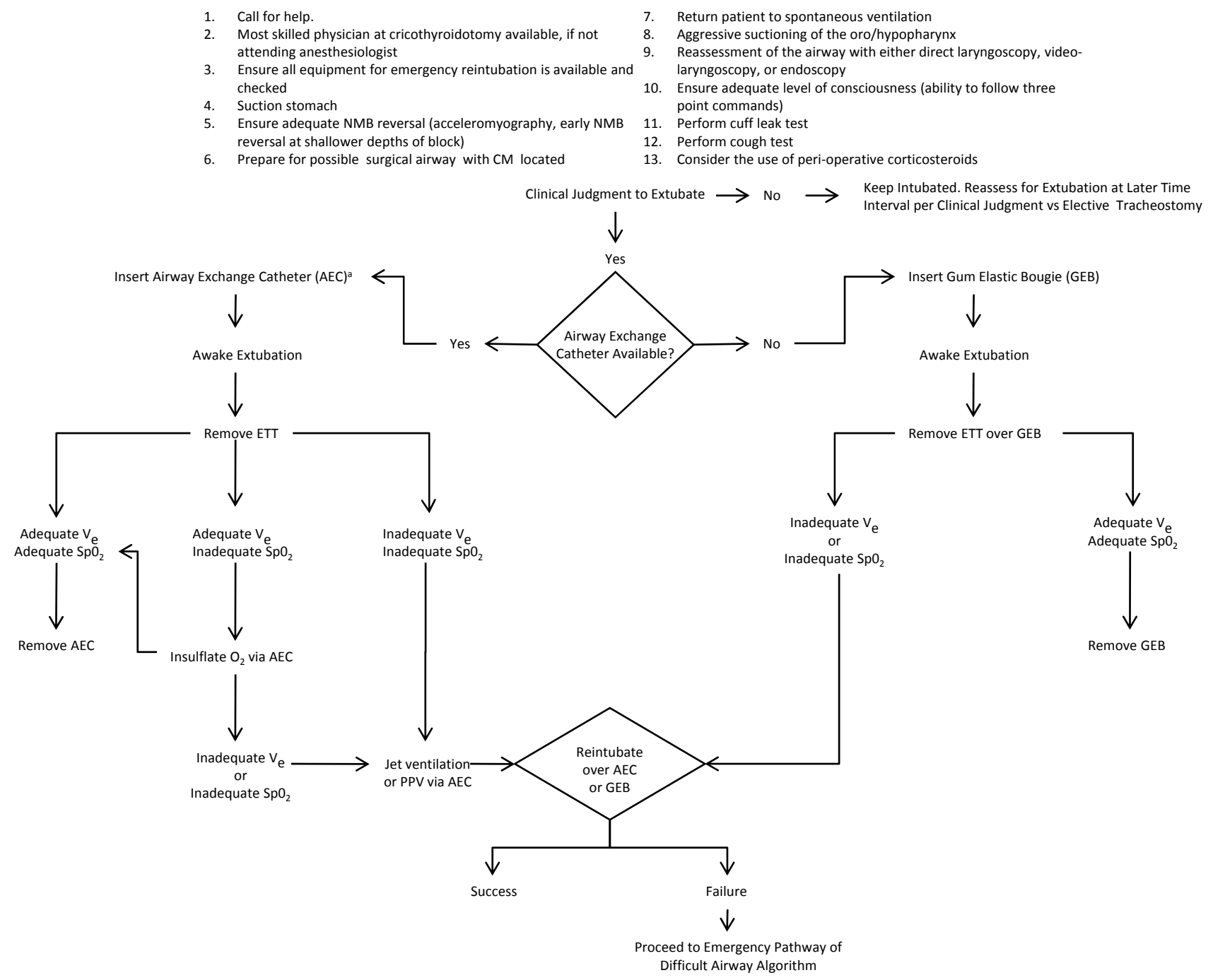

Fig. (1). Algorithm for Extubation of the Difficult Airway. This algorithm illustrates a stepwise approach for extubation of the difficult airway, as a compliment to the American Society of Anaesthesiologist's Difficult Airway Algorithm. Endotracheal tube (ETT), Airway exchange catheter (AEC), Gum elastic bougie (GEB), Positive Pressure Ventilation (PPV), Neuromuscular Blockade (NMB), Pulmonary Ventilation (Ve), Saturation of Hemoglobin with Oxygen as Measured by Pulse Oximetry (SpO2), Cricothyroid Membrane (CM).

anatomy might have changed since intubation, or surgical or anesthetic complications, such as bleeding, may have occurred. This assessment can be done with either direct laryngoscopy, video-laryngoscopy, or endoscopy. Additionally, as part of the preparation for a possible surgical airway we recommend identification beforehand of the cricothyroid membrane, either via palpation or with the assistance of ultrasound [41]. With regard to identification of the cricothyroid membrane, body mass index appears a factor in palpation difficulty, however, body mass index does not appear a factor in identification of the cricothyroid membrance with the use of ultrasound [41]. When initially calling for help, this should include a physician more skilled at cricothyroidotomy than the attending anesthesiologist if available.

Airway protection is the patient's ability to guard against aspiration and airway obstruction. This requires an adequate level of consciousness and sufficient cough strength [42-44]. As described by Smina, patients were more likely to fail extubation if they could not open eyes to command, follow objects with eyes, grasp hand, and stick out their tongue [44]. Additionally, aggressive suctioning is necessary as the ability to protect the airway is significantly more difficult with copious secretions. It was shown in the ICU setting that patients with secretions $>2.5 \mathrm{~mL} /$ hour had a relative risk of 3.0 to fail extubation.

Cough strength as a predictor of ability to tolerate extubation has been described in the critical care setting. One study showed that patients who were unable to cough on command or who had a peak expiratory flow (PEF) rate during a cough of $<35 \mathrm{~L} / \mathrm{min}$ had a relative risk of 6.9 for extubation failure, while another showed that if PEF during a cough was $\leq 60 \mathrm{~L} / \mathrm{min}$ the relative risk for extubation failure was $4.8[45,46]$ To assess PEF, a spirometer can be inserted into the ventilator circuit. Patients with $\mathrm{PEF} \leq 60 \mathrm{~L} / \mathrm{min}$ are five times more likely to require reintubation [42, 44] Another, simpler method of assessing cough strength, showed that with an index card held 1 to $2 \mathrm{~cm}$ from the 
end of the ETT, if a patient is unable to moisten the card after 3 to 4 coughs, they are three times more likely to fail extubation [47]. Though mentioned here, it is recognized that this technique is not in wide spread use, though its simplicity may offer a wider spread use in less equipped facilities.

In relation to PEF, it is noted that patients in the ICU setting likely experience significantly longer periods of mechanical ventilation, where deconditioning probably plays a larger role in decreasing cough strength. Largely for this reason, spontaneous breathing trails have become a standard in the ICU setting for assessment of the readiness of a patient to disassociate from the ventilator. In the operating, residual muscle paralysis, not deconditioning, is the larger culprit, and, hence, spontaneous breathing trials are not used in the OR [48, 49]. Thus, proper assessment of muscle paralysis prior to extubation is recommended. To this end it is noted that there is strong evidence that acceleromyography (quantitative) monitoring improves detection of small degrees (TOF ratios > 0.6) of residual blockade, and is recommended to be used as part of our algorithm to ensue more accurate assessment of block depth and effect of reversal in the extubation of the difficult to intubate patient, where every effort must be made to try and avoid what could be a life threatening reintubation attempt [48]. In addition, complete recovery of neuromuscular function is more likely when anticholinesterases are administered early (>15-20 minutes before tracheal extubation) and at a shallower depth of block (TOF count of 4) [48].

In our algorithm, in addition to assessment of adequate muscle paralysis reversal, though measurement of PEF offers a more objective assessment of cough strength, if this is not possible, one should test for the ability of the patient to cough on command. In one study looking at patients in the ICU, the risk of extubation failure was $24 \%$ in patients who did not cough on command [45].

Even though the above are offered as suggestions to follow in the extubation of the difficult to intubate patient, it is important to note that generally accepted thresholds of cough strength, level of consciousness, and suctioning frequency/volume that would indicate an absolute contraindication to extubation have not been established in the ICU patient, much less in the OR patient.

Airway patency refers to the ability of the patient to maintain an open airway from the mouth and/or nose to the gas exchanging portions of the lungs. In this regard, the usual largest obstacle for the anesthesiologist is patency of the tracheal lumen post-extubation. Risk factors for postextubation laryngeal edema include prolonged intubation (variably defined as 36 hours to 6 days), age greater than 80 years, a large endotracheal tube (greater than $8 \mathrm{~mm}$ in men or $7 \mathrm{~mm}$ in women), a ratio of endotracheal tube (ETT) to laryngeal diameter greater than 45 percent, a small ratio of patient height to ETT diameter, an elevated Acute Physiology and Chronic Health Evaluation II score (APACHE II), a Glasgow Coma Scale score (GCS) < 8, traumatic intubation, female gender, a history of asthma, excessive tube mobility due to insufficient fixation, aspiration, and the presence of an orogastric or nasogastric tube [50-55] (See Table 1).

A cuff leak refers to normal airflow around the ETT after the cuff is deflated. When a cuff leak is absent, it suggests a reduced space between the ETT and the larynx. Etiologies include laryngeal edema, laryngeal injuries, secretions, or a disproportionately large ETT for a patient's larynx size [56, 57]. Patients without a cuff leak are at increased risk of postextubation stridor which has been suggested as a risk factor for failed extubation. However, absence of a cuff leak alone is an inadequate predictor of post-extubation stridor, as a pooled analysis found a sensitivity and specificity of 56 and 92 percent, respectively [56]. Furthermore, it has been noted that many patients are safely extubated despite an absent cuff leak $[58,59]$. General speaking, if a cuff leak is detected, extubation will likely have a better chance of being successful.

A cuff leak may be measured qualitatively or quantitatively. The qualitative method involves placing a stethoscope over the trachea and listening for air while the cuff of the ETT is deflated. The quantitative method averages the lowest three of six expired tidal volumes and compares them to the delivered tidal volume on volume controlled ventilation. Volumes less than $110 \mathrm{ml}$ or less than 12 to 24 percent of delivered tidal volume are suggestive of decreased airway patency [50, 53, 60-63]. However, to reemphasize, though a cuff leak is suggested in our algorithm, it is important to note that some authors have found that failing the cuff leak test was not an accurate predictor of post-extubation stidor and should not be used as an absolute indication for delaying extubation [53]. In the future, ultrasound may become an established method of determining the width of the laryngeal air column during cuff deflation [64].

Table 1. Risk Factors for Post Extubation Laryngeal Edema

\begin{tabular}{|c|c|}
\hline - Prolonged intubation (variably defined as $36 \mathrm{hrs}$ to 6 days) & - $\mathrm{GCS}<8$ \\
\hline - Age greater than 80 years & - Traumatic intubation \\
\hline - Large ETT (greater than $8 \mathrm{~mm}$ in men or $7 \mathrm{~mm}$ in women) & - Female gender \\
\hline - Ratio of ETT to laryngeal diameter greater than 45 percent & - History of asthma \\
\hline - Small ratio of patient height to ETT diameter & - Excessive tube mobility due to insufficient fixation \\
\hline - Elevated APACHE II Score & - Aspiration \\
\hline$\bullet$ & - Presence of an orogastric or nasogastric tube \\
\hline
\end{tabular}

Acute Physiology and Chronic Health Evaluation II (APACHE II) Score, Glascow Coma Scale (GCS), Endotracheal tube (ETT). 
Though not examined specifically in the operating room setting, corticosteroids have been investigated to assess their ability to reduce the rate of extubation failure in intensive care patients of all age groups [65]. In an examination of fourteen RCTs including 2,600 participants of patients mechanically ventilated for 3-21 days, a reduction in reintubation with the use of corticosteroids was seen (OR 0.46 ), with an effect most pronounced in studies when used at least $12 \mathrm{~h}$ prior to attempted extubation (OR 0.41) [65]. A reduction in laryngeal edema was also seen (OR 0.36) [65].

In the ICU setting, methylprednisolone $(20 \mathrm{mg})$ administered every four hours for a total of four doses prior to extubation appears to be the most effective treatment [23, $50,51,65-67]$. However, given the usually shorter duration of perioperative care of the difficult to intubate patient, it is important to note that trials that examined a single dose of glucocorticoids shortly prior to extubation did not find a difference in outcomes [21, 26, 68]. This said, it appears reasonable that an argument could be made for the use of multiple doses of corticosteroids (methylprednisolone $20 \mathrm{mg}$ every four hours as time permits) in the difficult to intubate patient, however, definitive perioperative studies, including when to start treatment (pre-operatively or intraoperatively), as well as effective OR setting doses, need to be undertaken before such recommendations can be more reliably made.

Combining both a cuff leak test with a cough test may be the easiest method for the anesthesiologist to assess airway patency, assess the ability of the patient to protect the airway, and assess their level of consciousness by being able to follow commands. With the cuff deflated and the ETT occluded, a patient can be instructed to cough. In the critical care setting, absence of both an audible cuff leak and cough is indicative of a 10 fold increase in the development of post-extubation stridor [69]. Considering that both of these maneuvers are readily available in the OR setting, it seems reasonable to recommend their employment prior to prospective OR setting verification.

Since no one particular assessment test, or combination of tests, has been established as the gold standard for meeting extubation criteria, decisions regarding extubation must be made on an individual basis. At this point in time without further prospective verification of specific modalities for use in the OR setting, by combining assessment modalities, we believe the anesthesiologist will then be able to make the best clinical decision about extubation readiness. After all, arguably the best way to prevent a failed or traumatic reintubation in the difficult to intubate patient is the clinical judgment to not extubate in the first place. If the decision to not extubate is made, a reassessment of extubation can take place at an interval per the clinical judgment of the anesthesiologist, and the decision to pursue an extubation attempt at that time, versus allowing more time to pass prior to an attempted extubation (as in cases of temporary airway swelling), versus elective tracheostomy can be made.

\section{EXTUBATION PROCEDURE}

After assessment and compliance with the prerequisites listed before entering the algorithm tree, and determination that the patient is ready for attempted extubation, if possible, patients should be placed in the upright position; however, we note that further research into the use of this, and other, positions is required before making definitive recommendations as to the best position for extubation of the difficult to intubate patient in any setting [70]. Either an AEC or GEB should then be placed depending on the equipment available to the practitioner and their level of comfort using each device, prior to awake extubation. In order to prevent the aspiration of any supraglottic material during the immediate extubation period, patients should be instructed to take a deep breath prior to deflating their ETT cuff and removing the ETT. In the operating room, this last controlled breathe can be assisted with a single breathe of positive pressure during their inhalation cycle. Orogastric tubes should be removed prior to removal of the ETT to avoid accidental removal of the AEC or GEB.

When feasible, all prior monitors, except for devices such as transoesophageal echo probes, should remain on the patient during extubation and transport to the post anesthesia care unit (PACU) or ICU.

If the patient is oxygenating and ventilating appropriately, the AEC can be removed either in the OR, ICU, or in the PACU, depending on the practitioner's clinical judgment. However, regardless of the location of removal of the AEC or GEB, it is important that all resources required for emergency reintubation or a surgical airway be available in that location.

If the patient has adequate ventilation but inadequate oxygenation, oxygen can be insufflated via the AEC. If this resolves the problem, once it is reaffirmed that the patient can protect and maintain their airway, the AEC can be removed and the patient can continue receiving supplemental oxygen as needed. If the patient continues to have inadequate oxygenation, they have failed their trial of extubation, and immediate reintubation is required without delay by attempted reintubation over the AEC. However, if there is an unexpected delay in immediate reintubation, such as defective equipment or lack of required equipment, jet ventilation, or positive pressure ventilation, contingent on the internal diameter size of the AEC used, can be used as a temporizing procedure. If the reintubation effort is unsuccessful, one would then proceed to the ASA's difficult airway algorithm, and these temporizing procedures can also be used while provisions, such as a surgical airway, are undertaken.

It is noted that commercially available AECs come in myriad sizes ranging from 8 to $19 \mathrm{Fr}$, with respective internal diameters of 1.6 to $3.4 \mathrm{~mm}$, and adapters for both jet ventilation and positive pressure ventilation (via bag or the anesthesia machine). Depending on patient size, $1.6 \mathrm{~mm}$ would likely only accommodate jet ventilation, however, the larger $3.4 \mathrm{~mm}$ internal diameter tubes may be able to provide controlled oxygenation and ventilation in select patients. It is also noted that in the event of complete airway collapse, jet ventilation is contraindicated as it requires at least a partially patent airway to prevent hyperinflation and barotrauma.

If an AEC is not available, as may be the case in less equipped facilities, one can insert a GEB, and remove the ETT tube over it during awake extubation. Since the GEB is a solid device one cannot utilize it for oxygenation or ventilation if there is an unexpected delay in reintubation 
after a failed extubation. However, if after removal of the ETT over the GEB the patient has adequate oxygenation and ventilation, the GEB can be removed either in the OR, ICU, or the PACU, depending on the practitioner's clinical judgment.

Though the use of either an AEC or GEB has been advocated for planned extubation procedures, it is noted these devices are not free of potentially life-threatening complications themselves, and several have been reported $[9,71,72]$. These include barotrauma, bronchial damage, misguided catheters due to tube laceration or occlusion, accidental removal of the AEC or GEB before reintubation, and the inability to advance the ETT below the level of the vocal cords due to glottis edema [71, 73, 74]. Additionally, it has been noted that complications can occur more often in patients with difficult airways [71]. Thus, though an AEC or GEB is doubtless a well-established and successful method for reintubation in the difficult to intubate patient, and potentially life-saving, complications with their use are possible. Accordingly it is stressed that simultaneous provisions should be made for surgical airway procedures in any extubated difficult to intubate patient when an AEC or GEB are placed as part of this algorithm [71].

Currently, there are no evidence-based guidelines regarding the optimal period of time for maintaining airway access post-extubation via an indwelling AEC or GEB, with experts having suggested that the respective device should be left in place for at least 30-60 min or until the likelihood of reintubation is minimized [9, 19, 27, 28, 75]. However, with no firm guidelines, clinical judgment to balance the benefits and the risks of the leaving the AEC or GEB in place for shorter or longer periods of time is required.

Though our algorithm focuses on the extuabtion of the difficult to intubate patient in the immediate perioperative period, the practitioner should also be involved in the management planning of the patient should they begin to fail extubation in the extend perioperative period. Such planning by the practitioner should include ensuring that suctioning, bronchodilators, diuretics, and noninvasive positive pressure ventilation (NPPV) are immediately available, as, in many cases, aggressive early management can prevent reintubation. NPPV may prevent post-extubation respiratory failure if it is applied soon after extubation, particularly in the obese or those with chronic obstructive pulmonary disease [76-79]. However, care is taken to emphasize the application of this technique exceedingly early in the identification of a possible failing extubation, as NPPV appears ineffective and potentially harmful if it is not commenced until after the onset of post-extubation respiratory failure. Specific to this algorithm, its use in the OR or perioperative period is unclear at this time, and any employment of its use should be done in a guarded fashion so as to not lose the airway $[25,80]$.

\section{WHY THE ALGORITHM IS NEEDED}

Difficult airway management occurs when the anesthesiologist experiences difficulty with mask ventilation of the upper airway, tracheal intubation, or both. While there have been numerous attempts to predict which patients will pose problems with airway management, the difficult airway represents a complex interaction between patient factors, the clinical setting, and the skills of the practitioner. The fall in claims for adverse events related to the induction of anesthesia between 1993 and 1999 compared with 19851992 may be attributable in part to the creation of algorithms and guidelines for the anesthesiologist. Practice guidelines are systematically developed recommendations that assist in decision making, and while they are not intended to be standards or absolute requirements, they help provide a systematic approach to difficult airway management.

The Difficult Airway Algorithm prepared by the American Society of Anesthesiologists presents the basic tenets of preparedness and forethought. A recurring theme is that the practitioner should have numerous options based on the clinical situation. While this algorithm is likely to have had a beneficial impact of reducing complications in our patients with difficult airways, it also suggests a need for additional recommendations and strategies for difficult airway management during maintenance of anesthesia, as well as emergence and recovery.

In the authors' opinion, the algorithm presented in this manuscript will help serve this need by providing guidance towards a performulated stepwise approach to extubation of the difficult airway that provides modifiable options to fit into a local culture. Secondarily, this algorithm provides insight into the numerous areas in need of further investigation in the extubation of the difficult to intubate patient in the OR setting. Ultimately, as is needed of all algorithms, prospective verification is needed.

\section{FUNDING}

The authors have not received funding for this manuscript.

\section{CONFLICT OF INTEREST}

Declared none.

\section{ACKNOWLEDGEMENT}

Declared none.

\section{REFERENCE}

[1] Peterson GN, Domino KB, Caplan RA, Posner KL, Lee LA, Cheney FW. Management of the difficult airway: a closed claims analysis. Anesthesiology 2005; 103(1): 33-9.

[2] Cheney FW. The American society of anesthesiologists closed claims project: what have we learned, how has it affected practice, and how will it affect practice in the future? Anesthesiology 1999; 91(2): 552-6.

[3] Langeron O, Amour J, Vivien B, Aubrun F. Clinical review: management of difficult airways. Crit Care 2006; 10(6): 243.

[4] Lavery GG, McCloskey BV. The difficult airway in adult critical care. Crit Care Med 2008; 36(7): 2163-73.

[5] Practice guidelines for management of the difficult airway. A report by the American society of anesthesiologists task force on management of the difficult airway. Anesthesiology 1993; 78(3): 597-602.

[6] Antoine J, Hussain Z, El-Sayed I, Apfel CC. The unrecognised difficult extubation: a call for vigilance. Anaesthesia 2010; 65: 946-8.

[7] Lall NG. Difficult extubation. A fold in the endotracheal cuff. Anaesthesia 1980; 35(5): 500-1.

[8] Searl CP, Passey J. An unexpected difficult extubation. Anaesthesia 2000; 55(10): 1033-4. 
[9] Mort TC. Continuous airway access for the difficult extubation: the efficacy of the airway exchange catheter. Anesth Analg 2007; 105(5): 1357-62.

[10] Practice guidelines for management of the difficult airway: an updated report by the American society of anesthesiologists task force on management of the difficult airway. Anesthesiology 2003; 98(5): 1269-77.

[11] Hill RS, Koltai PJ, Parnes SM. Airway complications from laryngoscopy and panendoscopy. Ann Otol Rhinol Laryngol 1987; 96(6): 691-4.

[12] Mathew JP, Rosenbaum SH, O'Connor T, Barash PG. Emergency tracheal intubation in the postanesthesia care unit: physician error or patient disease? Anesth Analg 1990; 71(6): 691-7.

[13] Hines R, Barash PG, Watrous G, O'Connor T. Complications occurring in the postanesthesia care unit: a survey. Anesth Analg 1992; 74(4): 503-9.

[14] Perkins JD. Immediate tracheal extubation following liver transplantation. Liver Transpl 2006; 12(5): 883-4

[15] Kogan A, Ghosh P, Preisman S, et al. Risk factors for failed "fasttracking" after cardiac surgery in patients older than 70 years. J Cardiothorac Vasc Anesth 2008; 22(4): 530-5.

[16] Borracci RA, Dayan R, Rubio M, Axelrud G, Ochoa G, Rodriguez LD. Operating room extubation (ultra fast-track anesthesia) in patients undergoing on-pump and off-pump cardiac surgery. Arch Cardiol Mex 2006; 76(4): 383-9.

[17] Lanuti M, de Delva PE, Maher A, et al. Feasibility and outcomes of an early extubation policy after esophagectomy. Ann Thorac Surg. 2006; 82(6): 2037-41

[18] Bedger RC Jr, Chang JL. A jet-stylet endotracheal catheter for difficult airway management. Anesthesiology 1987; 66(2): 221-3.

[19] Loudermilk EP, Hartmannsgruber M, Stoltzfus DP, Langevin PB. A prospective study of the safety of tracheal extubation using a pediatric airway exchange catheter for patients with a known difficult airway. Chest 1997; 111(6): 1660-5.

[20] Rashkin MC, Davis T. Acute complications of endotracheal intubation. Relationship to reintubation, route, urgency, and duration. Chest 1986; 89(2): 165-7.

[21] Darmon JY, Rauss A, Dreyfuss D, et al. Evaluation of risk factors for laryngeal edema after tracheal extubation in adults and its prevention by dexamethasone. A placebo-controlled, double-blind, multicenter study. Anesthesiology 1992; 77(2): 245-51.

[22] Epstein SK. Decision to extubate. Intensive Care Med 2002; 28(5): 535-46.

[23] Epstein SK. Preventing postextubation respiratory failure. Crit Care Med 2006; 34(5): 1547-8.

[24] Epstein SK, Ciubotaru RL. Independent effects of etiology of failure and time to reintubation on outcome for patients failing extubation. Am J Respir Crit Care Med 1998; 158(2): 489-93.

[25] Esteban A, Frutos-Vivar F, Ferguson ND, et al. Noninvasive positive-pressure ventilation for respiratory failure after extubation. N Engl J Med 2004; 350(24): 2452-60.

[26] Ho LI, Harn HJ, Lien TC, Hu PY, Wang JH. Postextubation laryngeal edema in adults. Risk factor evaluation and prevention by hydrocortisone. Intensive Care Med 1996; 22(9): 933-6.

[27] Miller KA, Harkin CP, Bailey PL. Postoperative tracheal extubation. Anesth Analg 1995; 80(1): 149-72.

[28] Topf AI, Eclavea A. Extubation of the difficult airway. Anesthesiology 1996; 85(5): 1213-4.

[29] Crosby ET, Cooper RM, Douglas MJ, et al. The unanticipated difficult airway with recommendations for management. Can $\mathbf{J}$ Anaesth 1998; 45(8): 757-76.

[30] Schmidt U, Eikermann M. Organizational aspects of difficult airway management: think globally, act locally. Anesthesiology 2011; 114(1): 3-6.

[31] Karmarkar S, Varshney S. Tracheal extubation. Continuing Education in Anaesthesia. Critical Care \& Pain Br J Anaesth 2008; 8(6): 214-20.

[32] Asai T, Koga K, Vaughan RS. Respiratory complications associated with tracheal intubation and extubation. Br J Anaesth 1998; 80(6): 767-75.

[33] Rudra A, Chatterjee S. Tracheal extubation in the difficult airway. Indian J Anaesth 2006; 50(6): 430-4.

[34] Marks R, Tanner L, Wenleder B. Management of a tumor in the distal trachea while maintaining spontaneous ventilation. J Anesth 2010; 24(6): 932-4.
[35] Robles B, Hester J, Brock-Utne JG. Remember the gum-elastic bougie at extubation. J Clin Anesth 1993; 5(4): 329-31.

[36] Costa e Silva L, Brimacombe JR. Tracheal tube/laryngeal mask exchange for emergence. Anesthesiology 1996; 85(1): 218.

[37] Dob DP, Shannon CN, Bailey PM. Efficacy and safety of the laryngeal mask airway vs Guedel airway following tracheal extubation. Can J Anaesth 1999; 46(2): 179-81.

[38] Ellard L, Brown DH, Wong DT. Extubation of a difficult airway after thyroidectomy: use of a flexible bronchoscope via the LMAClassic. Can J Anaesth 2012; 59(1): 53-7.

[39] Koga K, Asai T, Vaughan RS, Latto IP. Respiratory complications associated with tracheal extubation. Timing of tracheal extubation and use of the laryngeal mask during emergence from anaesthesia. Anaesthesia 1998; 53(6): 540-4.

[40] Sasano H, Sasano N, Hattori T, Tsubouchi H, Tsuda T, Katsuya H. Tracheal tube/laryngeal mask exchange to prevent coughing in lung volume reduction surgery. Masui 2000; 49(3): 278-81.

[41] Nicholls SE, Sweeney TW, Ferre RM, Strout TD. Bedside sonography by emergency physicians for the rapid identification of landmarks relevant to cricothyrotomy. Am J Emerg Med 2008; 26(8): 852-6.

[42] Epstein SK. Putting it all together to predict extubation outcome. Intensive Care Med 2004; 30(7): 1255-7.

[43] Namen AM, Ely EW, Tatter SB, et al. Predictors of successful extubation in neurosurgical patients. Am J Respir Crit Care Med 2001; 163(3 Pt 1): 658-64.

[44] Smina M, Salam A, Khamiees M, Gada P, Amoateng-Adjepong Y, Manthous CA. Cough peak flows and extubation outcomes. Chest 2003; 124(1): 262-8.

[45] Beuret P, Roux C, Auclair A, Nourdine K, Kaaki M, Carton MJ. Interest of an objective evaluation of cough during weaning from mechanical ventilation. Intensive Care Med 2009; 35(6): 1090-3.

[46] Salam A, Tilluckdharry L, Amoateng-Adjepong Y, Manthous CA. Neurologic status, cough, secretions and extubation outcomes. Intensive Care Med 2004; 30(7): 1334-9.

[47] Khamiees M, Raju P, DeGirolamo A, Amoateng-Adjepong Y, Manthous CA. Predictors of extubation outcome in patients who have successfully completed a spontaneous breathing trial. Chest 2001; 120(4): 1262-70.

[48] Brull SJ, Murphy GS. Residual neuromuscular block: lessons unlearned. Part II: methods to reduce the risk of residual weakness. Anesth Analg 2010; 111(1): 129-40.

[49] Murphy GS, Brull SJ. Residual neuromuscular block: lessons unlearned. Part I: definitions, incidence, and adverse physiologic effects of residual neuromuscular block. Anesth Analg 2010; 111(1): 120-8.

[50] Cheng KC, Hou CC, Huang HC, Lin SC, Zhang H. Intravenous injection of methylprednisolone reduces the incidence of postextubation stridor in intensive care unit patients. Crit Care Med 2006; 34(5): 1345-50.

[51] Francois B, Bellissant E, Gissot V, Desachy A, et al. 12-h pretreatment with methylprednisolone versus placebo for prevention of postextubation laryngeal oedema: a randomised double-blind trial. Lancet 2007;369(9567): 1083-9.

[52] Friedman M, Baim H, Shelton V, et al. Laryngeal injuries secondary to nasogastric tubes. Ann Otol Rhinol Laryngol 1981; 90(5 Pt 1): 469-74.

[53] Kriner EJ, Shafazand S, Colice GL. The endotracheal tube cuffleak test as a predictor for postextubation stridor. Respir Care 2005; 50(12): 1632-8.

[54] Santos PM, Afrassiabi A, Weymuller EA Jr. Risk factors associated with prolonged intubation and laryngeal injury. Otolaryngol Head Neck Surg 1994; 111(4): 453-9.

[55] Sukhupanyarak S. Risk factors evaluation and the cuff leak test as predictors for postextubation stridor. J Med Assoc Thai 2008; 91(5): 648-53.

[56] Ochoa ME, Marin Mdel C, Frutos-Vivar F, et al. Cuff-leak test for the diagnosis of upper airway obstruction in adults: a systematic review and meta-analysis. Intensive Care Med 2009; 35(7): 1171-9.

[57] Wittekamp $\mathrm{BH}$, van Mook WN, Tjan DH, Zwaveling JH, Bergmans DC. Clinical review: post-extubation laryngeal edema and extubation failure in critically ill adult patients. Crit Care 2009; 13(6): 233.

[58] Engoren M. Evaluation of the cuff-leak test in a cardiac surgery population. Chest 1999; 116(4): 1029-31. 
[59] Fisher MM, Raper RF. The 'cuff-leak' test for extubation. Anaesthesia 1992; 47(1): 10-2.

[60] Miller RL, Cole RP. Association between reduced cuff leak volume and postextubation stridor. Chest 1996; 110(4): 1035-40.

[61] De Bast Y, De Backer D, Moraine JJ, Lemaire M, Vandenborght C, Vincent JL. The cuff leak test to predict failure of tracheal extubation for laryngeal edema. Intensive Care Med 2002; 28(9): 1267-72.

[62] Lee CH, Peng MJ, Wu CL. Dexamethasone to prevent postextubation airway obstruction in adults: a prospective, randomized, double-blind, placebo-controlled study. Crit Care 2007; 11(4): R72.

[63] Jaber S, Chanques G, Matecki S, et al. Post-extubation stridor in intensive care unit patients. Risk factors evaluation and importance of the cuff-leak test. Intensive Care Med 2003; 29(1): 69-74.

[64] Ding LW, Wang HC, Wu HD, Chang CJ, Yang PC. Laryngeal ultrasound: a useful method in predicting post-extubation stridor. A pilot study. Eur Respir J 2006; 27(2): 384-9.

[65] McCaffrey J, Farrell C, Whiting P, Dan A, Bagshaw SM, Delaney AP. Corticosteroids to prevent extubation failure: a systematic review and meta-analysis. Intensive Care Med 2009; 35(6): 977-86.

[66] Fan T, Wang G, Mao B, et al. Prophylactic administration of parenteral steroids for preventing airway complications after extubation in adults: meta-analysis of randomised placebo controlled trials. BMJ 2008; 337: a1841.

[67] Jaber S, Jung B, Chanques G, Bonnet F, Marret E. Effects of steroids on reintubation and post-extubation stridor in adults: meta-analysis of randomised controlled trials. Crit Care 2009; 13(2): R49.

[68] Khemani RG, Randolph A, Markovitz B. Corticosteroids for the prevention and treatment of post-extubation stridor in neonates, children and adults. Cochrane Database Syst Rev 2009(3): CD001000.

[69] Maury E, Guglielminotti J, Alzieu M, Qureshi T, Guidet B, Offenstadt G. How to identify patients with no risk for postextubation stridor? J Crit Care 2004; 19(1): 23-8.

[70] Rassam S, Sandbythomas M, Vaughan RS, Hall JE. Airway management before, during and after extubation: a survey of practice in the United Kingdom and Ireland. Anaesthesia 2005; 60(10): 995-1001.

[71] Heininger A, Krueger WA, Dieterich HJ, Konigsrainer I, Schroeder TH. Complications using a hollow fiber airway exchange catheter for tracheal tube exchange in critically ill patients. Acta Anaesthesiol Scand 2008; 52(7): 1031.

[72] Wise-Faberowski L, Nargozian C. Utility of airway exchange catheters in pediatric patients with a known difficult airway. Pediatr Crit Care Med 2005; 6(4): 454-6.

[73] Dobson G. The use of an airway exchange catheter in the management of acute airway obstruction. Eur J Anaesthesiol 2003; 20(11): 937-8.

[74] Eisenach JH, Barnes RD. Potential disaster in airway management: a misguided airway exchange catheter via a hole bitten into a univent endotracheal tube. Anesthesiology 2002; 96(5): 1266-8.

[75] Cooper RM. The use of an endotracheal ventilation catheter in the management of difficult extubations. Can J Anaesth 1996; 43(1): 90-3.

[76] El-Solh AA, Aquilina A, Pineda L, Dhanvantri V, Grant B, Bouquin P. Noninvasive ventilation for prevention of postextubation respiratory failure in obese patients. Eur Respir J 2006; 28(3): 588-95.

[77] Ferrer M, Sellares J, Valencia M, et al. Non-invasive ventilation after extubation in hypercapnic patients with chronic respiratory disorders: randomised controlled trial. Lancet 2009; 374(9695): 1082-8.

[78] Ferrer M, Valencia M, Nicolas JM, Bernadich O, Badia JR, Torres A. Early noninvasive ventilation averts extubation failure in patients at risk: a randomized trial. Am J Respir Crit Care Med 2006; 173(2): 164-70.

[79] Nava S, Gregoretti C, Fanfulla F, et al. Noninvasive ventilation to prevent respiratory failure after extubation in high-risk patients. Crit Care Med 2005; 33(11): 2465-70.

[80] Keenan SP, Powers C, McCormack DG, Block G. Noninvasive positive-pressure ventilation for postextubation respiratory distress: a randomized controlled trial. JAMA 2002; 287(24): 3238-44.

Received: December 05, 2011

Revised: January 17, 2012

Accepted: January 25, 2012

(C) Voscopoulos et al.; Licensee Bentham Open.

This is an open access article licensed under the terms of the Creative Commons Attribution Non-Commercial License (http://creativecommons.org/licenses/ by-nc/3.0/) which permits unrestricted, non-commercial use, distribution and reproduction in any medium, provided the work is properly cited. 